\title{
Economic justification of the choice of the thermal protection of buildings
}

\author{
Elena Malyavina ${ }^{1, *}$, and Anastasya Frolova $^{1}$ \\ ${ }^{1}$ Moscow State University of Civil Engineering, Yaroslavskoe shosse, 26, Moscow, 129337, Russia
}

\begin{abstract}
A large number of factors influence the economically feasible heat transfer resistance of the building enclosing structures. First of all, it is the cost of insulation and heat for the building heating in the cold season. As shown by studies, it is not enough for air-conditioned buildings. The result depends on the mode of the building operation in time and the heat load on the heating and cooling systems. Therefore, in addition to these significant factors of economic feasibility of the thermal protection level, there are the cost of electricity for the production of cold for cooling the building, the cost of the building heating and cooling systems and the cost of connection to power supply networks. The got result is important to convey to the professional community in a clear and compact form. In the present work the buildings of administrative and office purpose are considered, the working day of which lasts from 9-00 to 18-00 hours with different specific heat supply from 0 to $80 \mathrm{~W} / \mathrm{m}^{2}$ on the estimated area during working hours. Generalization of the research results is made on the basis of specific heat protection characteristics of the building, which is a product of the overall heat transfer coefficient of the building and the compactness coefficient. The total heat transfer coefficient of the building characterizes the heat losses and the heat inflows to the building through the enclosing structures, and the compactness coefficient can serve as an indicator of the surface area of the building, which is covered with insulation. For these buildings provision has been made for identification of the areas of the total discounted cost combination for all of the above components and the specific heat protection characteristics of the building relating to the feasibility of the specified level of the thermal protection.
\end{abstract}

\section{Introduction}

The economic aspect of choosing the thermal protection level of the buildings is under a close attention of specialists [1-11]. Moreover, the economic feasibility of the further increase in the thermal protection level is often questioned [12, 13].

Currently, the values of the basic level of the thermal protection in the Russian federation are normalized in the SP 50.13330.2012 "Thermal protection of buildings." These values were assigned by will in previous regulations in 2000 for implementation of

\footnotetext{
* Corresponding author: emal@list.ru
} 
the energy saving requirements in the buildings. The mentioned normative document allows to lower the heat transfer resistance of the enclosing structures in newly constructed and reconstructed buildings, if the specific consumption of the heat energy on heating and ventilation of these buildings is within the regulatory limits within the heating period.

In addition, in the reconstructed buildings, where for architectural or historical reasons it is impossible to provide the heat insulation of the walls outside, it is allowed to apply heat protection, which is based according to sanitary conditions.

The following results apply to the buildings with different specific internal heat inputs from 0 to $80 \mathrm{~W} / \mathrm{m}^{2}$, with the year-round maintenance of the allowed temperature conditions from $18{ }^{\circ} \mathrm{C}$ to $24{ }^{\circ} \mathrm{C}$ (the resulting temperature) during the working time from 9 to 18 hours in the building premises.

To identify economically feasible thermal protection, we proposed $[14,15]$ to compare different options of the building insulation by total discounted costs (TDC), which shall take into account all the expense components that are affected by the building thermal protection. These ones include $[16,17]$ the cost of insulation, the cost of heating and cooling systems of the building, the cost of connecting these systems to power lines, the cost of energy transfer agents. Of course, to clarify these costs of energy carrying agents and the connection of the object to the power supply networks, the calculations of the year energy consumption by the buildings have been previously performed $[18,19]$.

As a result of the research, the conditions under which different levels of thermal protection are economically feasible have been obtained, and the purpose of this article is to report them to the professional community in a clear and compact form.

\section{Initial data for calculations}

This study has adopted the options of the building sizes, which vary from each other by different lengths and different number of storeys. The width of the building is accepted in all cases the same and equal to $20.2 \mathrm{~m}$ in external measurement. All end walls are blind (without windows). The building has been examined in 3 (the building options $1-3$ ) and 12 (the building options $4-6$ ) floors. The share of glazing of longitudinal walls is presented in two versions: $0.25 ; 0.55$. The windows are dense enough to ignore the infiltration.

The buildings incorporate office rooms of the same size $6.8 \times 10.1 \times 3.9(\mathrm{~h}) \mathrm{m}$. Four types of rooms have been examined herein: ordinary on the intermediate floors, ordinary on the top floor, corner ones on the intermediate floors, corner ones on the top floor.

Three options of the building thermal protection have been examined being different from each other in the heat transfer resistance of the external walls and the coating. For the option 1, the heat transfer resistance of the outer wall and the coating is close to the level of the sanitary requirements. The option 3 of the thermal protection corresponds to the basic level of SP 50.13330.2012. For the option 2, the heat transfer resistance of the outer walls and coatings are calculated using a decreasing coefficient of 0.63 for the walls and 0.8 for the coating with respect to the option 3 , which have been adopted as the limiting ones in the above mentioned SP. The values of the heat transfer resistance, $\mathrm{m}^{2.0} \mathrm{C} / \mathrm{W}$ for external enclosing structures which correspond to the options 1, 2 and 3 according to the standards of Moscow are as follows: for the external walls: $1.254 ; 1.754 ; 2.629$; for the coatings: $1.3709 ; 2.871 ; 3.621$. The resistance to the heat transfer of the windows in all variants is taken to be equal to $0.54 \mathrm{~m}^{2.0} \mathrm{C} / \mathrm{W}$. Thus, it was considered about 200 options of the buildings, which differ from each other in size, thermal protection and glazing of the building facade.

Calculations of the energy consumption by the systems of maintaining the permissible temperature conditions have been performed at seven different values of the outdoor air 
temperature during the year: from the design for heating to the design for air conditioning in the warm period of the year. Thus, the whole year was divided into 7 intervals, in which the selected temperatures were the middle ones. The duration of the temperature observation in each interval was determined by [20].

For a more complete use of the available heat inputs in the room during the heating period, it was decided to maintain the resulting temperature throughout the working day from 18 to $24{ }^{\circ} \mathrm{C}$ and in the range of $22-24{ }^{\circ} \mathrm{C}$ during the working time of the warm season.

Two restrictions are imposed on the heating capacity at any temperature of the outside air. First, it should not exceed the power of heating, which maintains the temperature of $20{ }^{\circ} \mathrm{C}$ around the clock in the room. Secondly, the room temperature should not be below $18^{\circ} \mathrm{C}$ at the beginning of the working day and above $24^{\circ} \mathrm{C}$ by the end of the working time. The cooling flows were selected for each specific calculation option individually. At the same time, the room temperature did not exceed $24{ }^{\circ} \mathrm{C}$ throughout the day.

It is believed that all the heat excess is removed by the fan heat exchangers (fan coils). It is assumed that the condensers of the refrigerating machine are cooled by the $40 \%$ solution of ethylene glycol circulating through a dry cooling tower installed in the yard of the building or on its roof. In some periods of the year, the cooling is carried out by artificial or natural cooling. Moreover, the natural cooling is understood as the use in fancoils of water, which has been cooled in the drycooler .

Attention is drawn to the fact that only the need for buildings in the heat and cold to maintain a given thermal climate of the premises was taken into account. No losses due to inefficiency of operation and additional energy expenses for the preparation of the required heat carrying agents of heating and cooling systems were considered. In the calculations it was assumed that the natural cooling is used at a temperature of the outside air not higher than $+5^{\circ} \mathrm{C}$.

\section{Calculation results}

The results of economic calculations were summarized on the graphs, depending on the specific heat protection characteristics of the building $k$ shsc, which is equal to the product of the coefficients of compactness and the total heat transfer coefficient of the building. Figure 1 shows the graphs with the areas of combinations of $k_{\mathrm{shsc}}$ and TDC, related to the economic benefits of one of the three options of thermal protection while maintaining the building acceptable temperature conditions.

The cost of the building thermal insulation affects the profitability of the option of the insulation in the anti-phase to the cost of all other expense components. This follows from the fact that the more powerful the thermal protection, the cheaper everything else. This factor is reflected in the fact that the curves in figures relating to the dependence on the insulation are deployed in the other direction in relation to the graphs in figures, from those relating to the dependences of the option of insulation from the cost of equipment and network connection, as well as to the cost of the energy carrying agents. Therefore, the generalized zones of benefit of the insulation options depending on the $k_{\text {shsc }}$ are determined at the lowest, medium and high costs of the thermal insulation.

As can be seen from the figure 1, some design points related to the thermal protection of one level fall into the zones of economically feasible thermal insulation of the buildings of another level near the specified boundaries between the zones. This indicates that the boundaries between the zones of the reaonable thermal protection may slightly move in one direction or another due to the different changes during the working day of the indoor air temperature in different versions of the calculation. Different changes in the temperature of 
a)

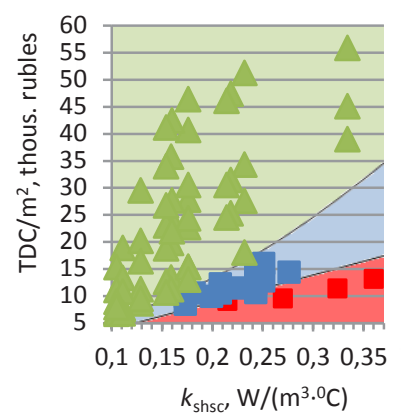

d)

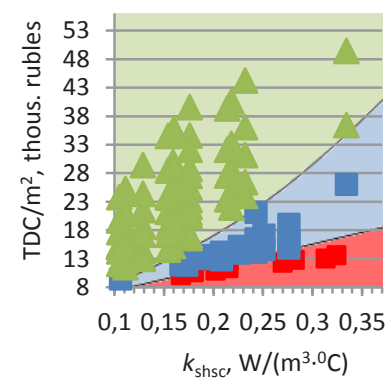

g)

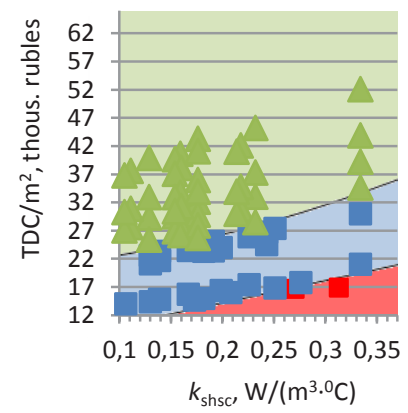

j)

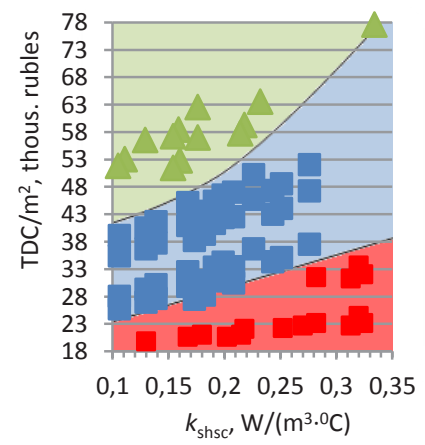

b)

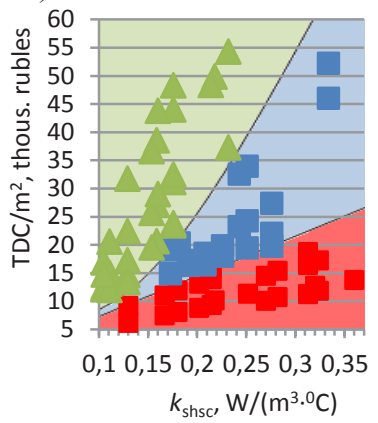

e)

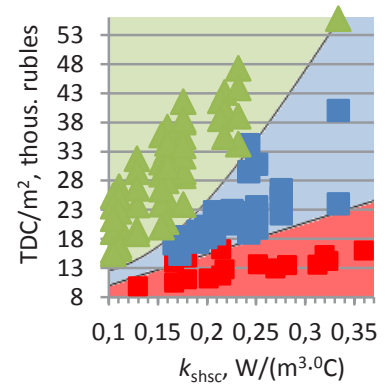

h)

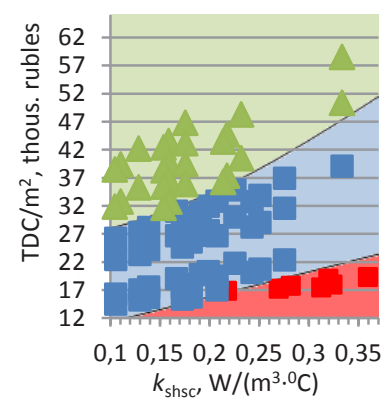

k)

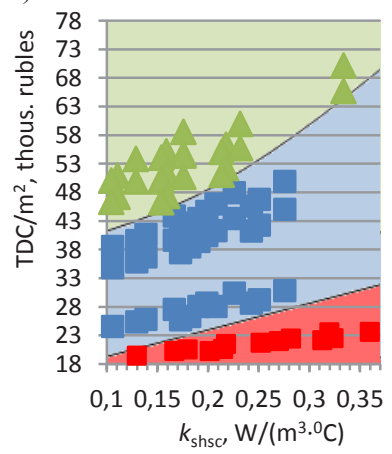

c)



f)



i)

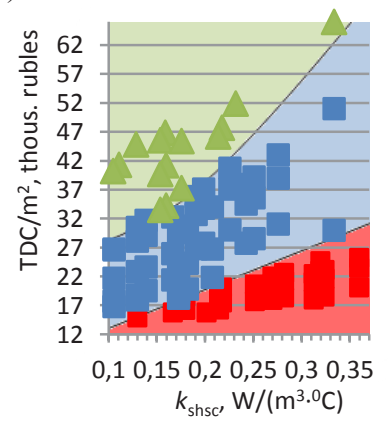

1)



Fig. 1. Economically effective options of thermal insulation of the buildings (red - option 1, blue option 2, green - option 3) when changing the specific thermal characteristics of the buildings $k_{\text {shsc }}$, $\mathrm{W} /\left(\mathrm{m}^{3 \cdot 0} \mathrm{C}\right)$, with the cost of insulation $9000 \mathrm{rubles} / \mathrm{m}^{3}(\mathrm{a}, \mathrm{d}, \mathrm{g}, \mathrm{j})$, with the cost of insulation 15000 rubles $/ \mathrm{m}^{3}$ (b, e, h, k), with the cost of insulation $22000 \mathrm{rubles} / \mathrm{m}^{3}$ (c, f, i, l). With the internal heat inflows $a, b, c-0-10 \mathrm{~W} / \mathrm{m}^{2}, \mathrm{~d}, \mathrm{e}, \mathrm{f}-15-30 \mathrm{~W} / \mathrm{m}^{2}, \mathrm{~g}, \mathrm{~h}, \mathrm{i}-40-50 \mathrm{~W} / \mathrm{m}^{2}, \mathrm{j}, \mathrm{k}, \mathrm{l}-60-80 \mathrm{~W} / \mathrm{m}^{2}$. At a discount rate of $10 \%$. 
the premises within the permissible limits differently influenced the accounting of the energy consumption by systems of maintaining the microclimate in them.

The presented graphs in figure 1 confirm the well-known thesis that the cheaper is the insulation, the more profitable is the option of the greater insulation. The graphs also show that the thermal protection according to the sanitary conditions is beneficial for lower values of TDC $/ \mathrm{m}^{2}$, that is, close to the minimum cost of heating and cooling systems, their connection to the power supply networks, heat and electricity. Moreover, the more expensive is the thermal protection, the higher is the price of these expenses, the option of thermal protection by sanitary conditions remains profitable. It is also interesting that in the buildings of a small volume (with high $k_{\text {shsc }}$ values) the thermal protection according to sanitary conditions is beneficial at higher $\mathrm{TDC} / \mathrm{m}^{2}$ than in the buildings of a larger volume.

If we take the discount rate not $10 \%$, but $5 \%$, as it was shown by calculations, nothing changes. Only TDC values have decreased.

If the total discounted expenses takes into account only the cost of the insulation and the heat, the picture of cost-effective heat resistance transfer zones of the building will be completely different. Some of the results of this calculation are shown in figure 2 . These results indicate that for the correct assessment of the feasibility of a particular level of the thermal protection it is necessary to take into account all the components of the cost of year-round maintenance of the microclimate in the office building rooms. For the buildings, in which the required microclimate parameters are maintained all the year-round, it is at least incorrect to find out the economically feasible option of the thermal protection only in comparison with the expenses to the building heat insulation and its heating. All components of capital and operating expenses should be taken into account, as shown by a comparison of the figures 1 and 2 .

a)

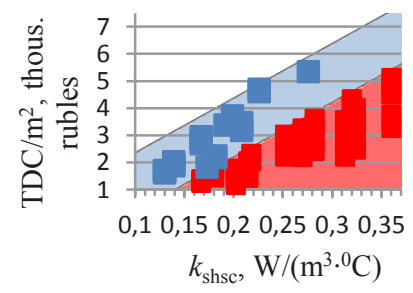

d)

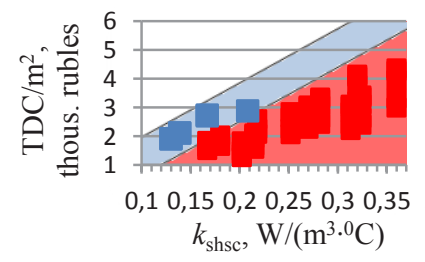

g)

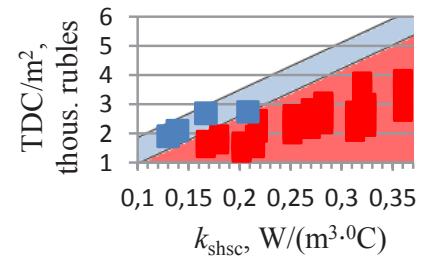

b)

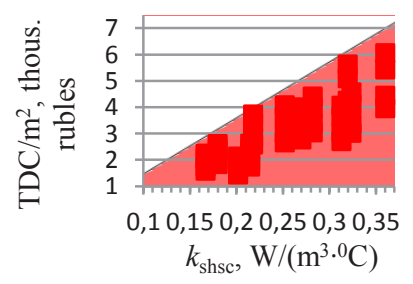

e)

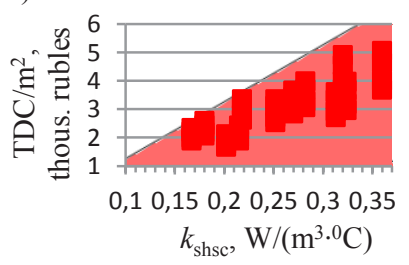

h)

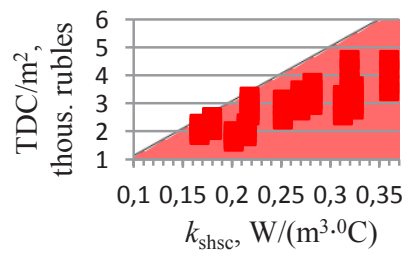

c)

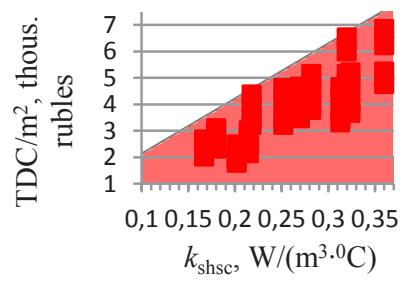

f)

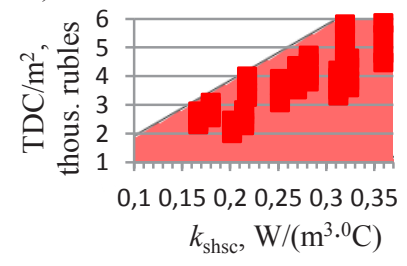

i)



Fig. 2. Zones of economically feasible options for thermal insulation of the buildings (red - option 1, blue - option 2, green - option 3) at the cost of insulation a, d, g - 9000 rubles $/ \mathrm{m}^{3}$; b, e, h - 15000 rubles $/ \mathrm{m}^{3}$; c, f, i - 22000 rubles $/ \mathrm{m}^{3}$; with internal heat inflows a, b, c-30 W/m $/ \mathrm{m}^{2}$, d, e, f - $50 \mathrm{~W} / \mathrm{m}^{2}$, g, $\mathrm{h}, \mathrm{j}-70 \mathrm{~W} / \mathrm{m}^{2}$, at the discount rate of $10 \%$. 


\section{Conclusions}

1. To provide the economic justification of the level of the building thermal protection with the internal heat emissions, in which the parameters of the internal environment are maintained all the year-round, it is necessary to consider energy expenses throughout the year: not only for heating of the building, but also for cooling. Consideration shall be made of all the expenses that are affected by the thermal protection of the building as capital ones - the cost of the building thermal insulation, equipment, heating and cooling, joining of the systems to the utility network, as operating costs cost of heat, electricity and depreciation payments.

2. Taking into account the change in the discount rate when calculating the TDCs from $5 \%$ to $10 \%$ does not lead to any tangible change in the zones of expediency of choosing the level of thermal protection.

3. The heat insulation according to the basic version in all buildings is advantageous at high TDC values $/ \mathrm{m}^{2}$, i.e. with more expensive heating and cooling systems, larger costs of connection to power lines and high cost of heat and electricity; the thermal protection according to sanitary conditions is beneficial at lower TDC values $/ \mathrm{m}^{2}$. The more expensive is the thermal protection, the higher is the price of these components, the option of the thermal protection for sanitary conditions remains profitable. The cheaper the insulation of the building is, the more profitable the option of the reinforced insulation is. In buildings of a small volume the thermal protection according to the sanitary requirements is favorable at higher $\mathrm{TDC} / \mathrm{m}^{2}$, than in the buildings of a bigger volume.

\section{References}

1. P.A. Muravyev, M.A. Lukina-Lebedeva, A.V. Tarakin, A.S. Gorshkov, Roofing and insulation materials 1, 21 - 29 (2017)

2. S.I. Lapteva, M.Z. Polyakova, Economics and entrepreneurship 10 - 1 (876 - 1), 724 727 (2017)

3. O.P. Makarova, G.V. Krasil'nikova, Modern problems and prospects of socioeconomic development of enterprises, industries, regions, 37 - 41 (2016)

4. G.P. Vasiliev, Energy saving 6, $14-23$ (2011)

5. E.M. Rezanov, P.V. Petrov, Papers of the conference: International scientific and practical conference. Topical energy issues, 18 - 21 (2017)

6. T. Hong, L. Yang, D. Hill, et al., Applied Energy 126, 90 - 106 (2014)

7. H. Orr, J. Wang, D. Fetsch, R. Dumont, Journal of Building Physics 36, $294-307$ (2013)

8. M. D’Orazio, C. Di. Perna, E. Di. Giuseppe, M. Morodo, Journal of Building Physics 36, $229-246$ (2013)

9. S. Asadi, M.M. Hassan, A. Beheshti, Journal of Building Physics 36, 247 - 264 (2013)

10. Y. Cheng, J. Nin, N. Gao, Building and Environment 47, 13 - 22 (2012)

11. A. Alajmi, Energy and Buildings 47, 122 - 130 (2012)

12. T.A. Skorik, E.K. Glazunova, A.V. Bezuglyy, Papers of the conference: Transport2017, 163 - 167 (2017)

13. Yu.I. Tostova, Papers of the conference: Energy saving and energy efficiency in industrial enterprises and in housing and communal services, 188 - 194 (2017) 
14. E.G. Malyavina, A.A. Frolova, Bulletin of BSTU named after V.G. Shukhov 8, $64-69$ (2017)

15. A.A. Frolova, C.O.K. 2, $54-57$ (2017)

16. E.G. Malyavina, A.A. Frolova, High school Bulletin. Construction 4, 78 - 83 (2013)

17. A.A. Frolova, A.V. Savina, O.V. Astanina, A.N. Barbarova, Success of the modern science and education 12(5), 62 - 64 (2016)

18. E.G. Malyavina, A.A. Frolova, AVOK 1, 18 - 23 (2017)

19. E.G. Malyavina, A.A. Frolova, Proceedings of the university investments. Construction. Real estate 11-12, 71 - 78 (2012)

20. V.K. Savin, Construction climatology: Reference book to SniP 23-01-99* (Sc. And research institute of the construction physics of RAASN, Moscow, 2006) 